\title{
GLOBAL RESEARCH OUTPUT ON CRYSTALLOGRAPHY: A SCIENTOMETRIC STUDY
}

\author{
SELVI. M G ${ }^{1} \&$ GOPALAKRISHNAN $S^{2}$ \\ ${ }^{1}$ Research Scholar, Bharathiar University, Coimbatore, Tamil Nadu, India \\ ${ }^{2}$ Head Resource Centre, National Institute of Fashion Technology, Taramani, Chennai, Tamil Nadu, India
}

\begin{abstract}
In this paper, the authors aim to identify the growth of research output on Crystallography. For this study, the data were downloaded from the multi discipline citation database 'Scopus' and there were2, 00,598 records contributed worldwide, over a period of 44 years from 1970-2013. Bibliometric techniques such as year wise distribution, bibliographic form of the records, area and sub field of research, source titles and research organizations were studied. Among them, 60,181 (30.00\%) publications were contributed by USA, and it holds first place. India holds 7 th place with $8,143(4.06 \%)$ publications.

KEYWORDS: Bibliometric Study, Growth and Research Output, Crystallography \& Scientometric
\end{abstract}

Received: May 02, 2017; Accepted: May 17, 2017; Published: May 20, 2017; Paper Id.: IJLSRJUN20174

\section{INTRODUCTION}

Bibliometric analysis is employed by researchers to study the growth of literature in a given field. Pritchard (1969) defined the term Bibliometric, as the application of statistical and mathematical methods to books and other communication. The bibliometrics has emerged as a thrust area of research, incorporating different branches of human knowledge. There are famous Laws of Bibliometric i.e. Lotka's law (1926) of scientific productivity, Bradford's law (1934) of scattering and Zipf's law (1949) on the frequency of words. But, the Bibliometric studies started in the late sixties.

The term 'Scientometric' was introduced and came into prominence with the founding of Journals named "Scientometrics" by Braun, originally published in Hungary and now in Amsterdam. According to Nalimove and Mulchentko (1969), Scientometric as the applications of those Quantitative methods, which are dealing with the analysis of Science, viewed as an information process in 1969. "Scient006Fmetrics is the study of the Quantitative aspects of Science, as a discipline or economic activity. It is part of the Sociology and has applied to Science Policy making. Scientometrics involves quantitative studies of scientific activities including, among others, publications and overlaps bibliometrics to some extent".

\section{CRYSTALLOGRAPHY}

Crystallography is the experimental science of determining the arrangement of atoms in the crystalline solids (crystal structure). The word "crystallography" derives from the Greek words crystallon "cold drop, frozeI drop", with its meaning extending to all solidscrystalline degree of transparency, and graphein "to write". In July 2012, the United Nations recognized the importance of the science of crystallography by proclaiming that 2014 would be the International Year of Crystallography. Crystallographic methods now depend on analysis of 
the diffraction patterns of a sample targeted by a beam of some type. X-rays are most commonly used; other beams used include, electrons or neutrons. This is facilitated by the wave properties of the particles. Crystallographers often explicitly state the type of beam used, as in the terms X-ray crystallography, neutron diffraction and electron diffraction.

$\mathrm{X}$-ray crystallography is used to determine the structure of large bio molecules, such as proteins. Before the development of X-ray diffraction crystallography (see below), the study of crystals was based on physical measurements of their geometry. This involved measuring the angles of crystal faces relative to each other and to theoretical reference axes (crystallographic axes), and establishing the symmetry of the crystal in question. This physical measurement is carried out using a gonio meter. The position in 3D space of each crystal face is plotted on a stereographic net such as a Wulff net or Lambert net. The pole to each face is plotted on the net. Each point is labeled with its Miller index. The final plot allows the symmetry of the crystal to be established.

\section{REVIEW OF RELATED LITERATURE}

In the recent past, the study of scientometric, bibliometric and other related areas is increasing, which results in bringing out the type of publications and the literature published in the research. . The derived statistics that measure the contribution of scientific publications within a given topic could represent the current research trends and also used to identify the focus on new research area, (Garfield, 1979) and helps in mapping of two different knowledge domains (Su HN, 2010). "Mooghali, et al., 2011) gave a complete review of the evolution of the field of scientometrics based on its literature published during 1980 and 2009." Global trends in the publications on various areas have been studied widely by various authors (Kalaiselvi 2017; Yang, et al., 2012; Ramesh 2014, Balasubmanian, 2014, Gopalakrishnan, 2015, Venkatesan, 2013). These studies gave a picture on the no. of publications published during a particular period, including the no. of publications, authorship pattern, language of publication and so on. Like the global trends, there has been no. of authors attempted on the growth of literature in a particular region in various areas (Karpagam et al., 2011, Keerti and Kumar 2011, Ramesh et al. 2014). Based on the studies, the authors of this paper attempted to study the growth of Indian brain tumor literature compared with the global output.

\section{OBJECTIVES OF THE STUDY}

The objectives of the study are

- To examine the worldwide research production in crystallography during the period 1970-2013.

- To identify the document type of the publications in crystallography.

- To identify the organizations conducting the research in crystallography.

- To compare and measure the growth rate of literature published during the period 1970-2013.

- To identify and analyze the research contribution in the subject field of crystallography.

- To identify the top source titles those carry the research productions in crystallography.

\section{HYPOTHESES}

The following hypotheses are formulated for this study based on objectives.

- There are more literatures published worldwide on crystallography. 
- Growth of publications in genetic engineering is comparatively higher in developing countries.

- The research productivity in crystallography is dominated by English language.

- Journals are a major source of publications for crystallography.

- There exists no steady growth in publication production in crystallography research.

\section{METHODOLOGY}

For this study, the literature on crystallography downloaded 'Scopus', an online multidisciplinary database which is an international indexing and abstracting database. The term 'crystallography' was used for retrieving literatures. The data collected for the study period from 1970 to 2013. The collected data have been classified using Microsoft Excel for the purpose of analysis. Statistical tools such as frequency distribution, percentage analysis and Bibliometric techniques such as Relative Growth Rate (RGR) and Doubling time (dt) were used for the study. Analysis on year wise distribution, subject coverage and organizations which contributed papers was covered.

\section{DATA ANALYSIS}

\section{Year Wise Distribution of Publications}

The year wise distributions of research publications contributed in crystallography are given in Table 1. The RoG, CAGR along with the no. of publications are shown in table 1.

Table 1: Year Wise Distribution of Publications

\begin{tabular}{|c|c|c|c|c|c|c|c|}
\hline S. No & Year & Publications & $\%$ & Cum & Cum \% & RoG & CAGR \\
\hline 1 & 1970 & 299 & 0.15 & 299 & 0.15 & 0.98 & 1.08 \\
\hline 2 & 1971 & 293 & 0.15 & 592 & 0.30 & 1.12 & 1.09 \\
\hline 3 & 1972 & 329 & 0.16 & 921 & 0.46 & 1.19 & 1.09 \\
\hline 4 & 1973 & 392 & 0.20 & 1313 & 0.66 & 1.06 & 1.08 \\
\hline 5 & 1974 & 414 & 0.21 & 1727 & 0.86 & 0.80 & 1.08 \\
\hline 6 & 1975 & 332 & 0.17 & 2059 & 1.03 & 0.97 & 1.09 \\
\hline 7 & 1976 & 323 & 0.16 & 2382 & 1.19 & 1.19 & 1.10 \\
\hline 8 & 1977 & 385 & 0.19 & 2767 & 1.38 & 1.01 & 1.09 \\
\hline 9 & 1978 & 389 & 0.19 & 3156 & 1.57 & 1.17 & 1.10 \\
\hline 10 & 1979 & 457 & 0.23 & 3613 & 1.80 & 0.86 & 1.09 \\
\hline 11 & 1980 & 395 & 0.20 & 4008 & 2.00 & 1.13 & 1.10 \\
\hline 12 & 1981 & 446 & 0.22 & 4454 & 2.22 & 1.15 & 1.10 \\
\hline 13 & 1982 & 513 & 0.26 & 4967 & 2.48 & 1.13 & 1.10 \\
\hline 14 & 1983 & 579 & 0.29 & 5546 & 2.77 & 1.25 & 1.10 \\
\hline 15 & 1984 & 722 & 0.36 & 6268 & 3.13 & 1.16 & 1.09 \\
\hline 16 & 1985 & 834 & 0.42 & 7102 & 3.54 & 1.05 & 1.09 \\
\hline 17 & 1986 & 877 & 0.44 & 7979 & 3.98 & 0.95 & 1.09 \\
\hline 18 & 1987 & 832 & 0.41 & 8811 & 4.39 & 1.15 & 1.10 \\
\hline 19 & 1988 & 959 & 0.48 & 9770 & 4.87 & 1.30 & 1.10 \\
\hline 20 & 1989 & 1249 & 0.62 & 11019 & 5.49 & 1.07 & 1.09 \\
\hline 21 & 1990 & 1332 & 0.66 & 12351 & 6.16 & 1.38 & 1.09 \\
\hline 22 & 1991 & 1834 & 0.91 & 14185 & 7.07 & 1.02 & 1.08 \\
\hline 23 & 1992 & 1868 & 0.93 & 16053 & 8.00 & 1.12 & 1.08 \\
\hline 24 & 1993 & 2100 & 1.05 & 18153 & 9.05 & 1.52 & 1.08 \\
\hline 25 & 1994 & 3192 & 1.59 & 21345 & 10.64 & 1.17 & 1.06 \\
\hline 26 & 1995 & 3720 & 1.85 & 25065 & 12.50 & 1.23 & 1.06 \\
\hline 27 & 1996 & 4586 & 2.29 & 29651 & 14.78 & 1.15 & 1.05 \\
\hline 28 & 1997 & 5268 & 2.63 & 34919 & 17.41 & 1.03 & 1.04 \\
\hline
\end{tabular}




\begin{tabular}{|c|c|c|c|c|c|c|c|}
\hline \multicolumn{9}{|c|}{ Table 1: Contd., } \\
\hline 29 & 1998 & 5434 & 2.71 & 40353 & 20.12 & 1.19 & 1.04 \\
\hline 30 & 1999 & 6463 & 3.22 & 46816 & 23.34 & 1.17 & 1.03 \\
\hline 31 & 2000 & 7590 & 3.78 & 54406 & 27.12 & 0.99 & 1.02 \\
\hline 32 & 2001 & 7496 & 3.74 & 61902 & 30.86 & 1.17 & 1.03 \\
\hline 33 & 2002 & 8777 & 4.38 & 70679 & 35.24 & 1.21 & 1.01 \\
\hline 34 & 2003 & 10618 & 5.29 & 81297 & 40.53 & 1.16 & 1.00 \\
\hline 35 & 2004 & 12265 & 6.11 & 93562 & 46.64 & 1.02 & 0.98 \\
\hline 36 & 2005 & 12506 & 6.23 & 106068 & 52.88 & 1.09 & 0.98 \\
\hline 37 & 2006 & 13601 & 6.78 & 119669 & 59.66 & 1.11 & 0.97 \\
\hline 38 & 2007 & 15125 & 7.54 & 134794 & 67.20 & 0.93 & 0.95 \\
\hline 39 & 2008 & 14096 & 7.03 & 148890 & 74.22 & 0.70 & 0.95 \\
\hline 40 & 2009 & 9851 & 4.91 & 158741 & 79.13 & 1.04 & 1.01 \\
\hline 41 & 2010 & 10262 & 5.12 & 169003 & 84.25 & 1.02 & 1.00 \\
\hline 42 & 2011 & 10437 & 5.20 & 179440 & 89.45 & 1.03 & 1.00 \\
\hline 43 & 2012 & 10756 & 5.36 & 190196 & 94.82 & 0.97 & 0.98 \\
\hline 44 & 2013 & 10402 & 5.19 & 200598 & 100.00 & 19.28 & 1.00 \\
\hline & Total & $\mathbf{2 0 0 5 9 8}$ & $\mathbf{1 0 0 . 0 0}$ & & & & \\
\hline & Avg Paper & $\mathbf{4 5 5 9 . 0 4 5}$ & & & & & \\
\hline
\end{tabular}

It can be seen from table 1 that, a total of 200598 research publications in Crystallography over the period of 44 years from 1970 to 2013 were published, with an average of 4559 articles per year. The highest number of publications can be seen in the year 2007, which amounts to 15,125 (7.54\%) articles followed by the year 2008 amounting to 14,096 $(7.03 \%)$.

\section{Relative Growth Rate and Doubling Time $\operatorname{dt}()$}

The Relative Growth Rate (RGR) is the increase in the number of articles/pages per unit of time. This definition is derived from the definition of relative growth rates in the study of growth analysis of individual plants, and effectively applied in the field of botany (Hunt, R 1978), which in turn, had its origin from the study of the rate of interest in the financial investment (Blackman, V.H. 1919). The mean Relative Growth Rate (RGR) over the specific period of interval can be calculated from the following equation:

$$
\log _{\varepsilon} W-\log _{\varepsilon} W
$$

RGR $1-2^{\bar{R}}=$

$$
{ }_{2}^{T}{ }_{-1} T
$$

Where as

$1-2 \bar{R}=$ Mean relative growth rate over the specific period of interval

$\log _{e l} W=\log$ of initial number of articles/pages

$\log _{e 2} \mathrm{~W}=\log$ of final number of articles/pages after a specific period of interval

${ }_{2} T-{ }_{1} T=$ The unit difference between the initial time and the final time

The year can be taken here as the unit of time. The RGR for both articles and pages can be calculated separately. Therefore

- $\quad 1-2^{\mathrm{R}}($ aa -1 year -1$)$ can represent the mean relative growth rate per unit of articles per unit of year over a specific 
period of interval and

- $\quad 1-2^{\mathrm{R}}$ (pp -1 year -1$)$ can represent the mean relative growth rate per unit of pages per unit of year over a specific period of interval.

\section{Doubling Time (Dt (p))}

There exists a direct equivalence between the relative growth rate and the doubling time. If the number of articles/pages on a subject doubles during a given period, then the difference between the logarithms of numbers at the beginning and end of this period must be the logarithms of number 2. If natural logarithm is used, this difference has a value of 0.693 . Thus the corresponding doubling time for each specific period of interval and for both articles and pages can be calculated by the following formula:

Doubling time $(\mathrm{Dt})=\log _{\mathrm{e}} 2 / \overline{\mathrm{R}}$

Therefore

$\log _{e} 2$

Doubling time for articles $\mathrm{Dt}(\mathrm{a})=$

$$
1-2 \overline{\mathrm{R}}(\text { aa-1 year-1) }
$$

$\log _{\mathrm{e}} 2=0.693$

The research productivity on Crystallograpy have been measured based on the Relative Growth Rate (RGR) and the doubling time (Dt ()). The relative growth rate and doubling time have been calculated and the same is shown in table 2 and figures 1 and 2 .

Table 2: Relative Growth Rate and doubling time

\begin{tabular}{|c|c|c|c|c|c|c|c|c|c|}
\hline S. No & Year & Publications & \% & Cum & Cum\% & w1 & w2 & RGR & Dt \\
\hline 1 & 1970 & 299 & 0.15 & 299 & 0.15 & & 5.700444 & 5.70 & 0.12 \\
\hline 2 & 1971 & 293 & 0.15 & 592 & 0.30 & 5.700444 & 6.383507 & 0.68 & 1.01 \\
\hline 3 & 1972 & 329 & 0.16 & 921 & 0.46 & 6.383507 & 6.82546 & 0.44 & 1.57 \\
\hline 4 & 1973 & 392 & 0.20 & 1313 & 0.66 & 6.82546 & 7.18007 & 0.35 & 1.95 \\
\hline 5 & 1974 & 414 & 0.21 & 1727 & 0.86 & 7.18007 & 7.454141 & 0.27 & 2.53 \\
\hline 6 & 1975 & 332 & 0.17 & 2059 & 1.03 & 7.454141 & 7.629976 & 0.18 & 3.94 \\
\hline 7 & 1976 & 323 & 0.16 & 2382 & 1.19 & 7.629976 & 7.775696 & 0.15 & 4.76 \\
\hline 8 & 1977 & 385 & 0.19 & 2767 & 1.38 & 7.775696 & 7.925519 & 0.15 & 4.63 \\
\hline 9 & 1978 & 389 & 0.19 & 3156 & 1.57 & 7.925519 & 8.057061 & 0.13 & 5.27 \\
\hline 10 & 1979 & 457 & 0.23 & 3613 & 1.80 & 8.057061 & 8.192294 & 0.14 & 5.12 \\
\hline 11 & 1980 & 395 & 0.20 & 4008 & 2.00 & 8.192294 & 8.296048 & 0.10 & 6.68 \\
\hline 12 & 1981 & 446 & 0.22 & 4454 & 2.22 & 8.296048 & 8.401558 & 0.11 & 6.57 \\
\hline 13 & 1982 & 513 & 0.26 & 4967 & 2.48 & 8.401558 & 8.510571 & 0.11 & 6.36 \\
\hline 14 & 1983 & 579 & 0.29 & 5546 & 2.77 & 8.510571 & 8.620832 & 0.11 & 6.29 \\
\hline 15 & 1984 & 722 & 0.36 & 6268 & 3.13 & 8.620832 & 8.743213 & 0.12 & 5.66 \\
\hline 16 & 1985 & 834 & 0.42 & 7102 & 3.54 & 8.743213 & 8.868132 & 0.12 & 5.55 \\
\hline 17 & 1986 & 877 & 0.44 & 7979 & 3.98 & 8.868132 & 8.984568 & 0.12 & 5.95 \\
\hline 18 & 1987 & 832 & 0.41 & 8811 & 4.39 & 8.984568 & 9.083756 & 0.10 & 6.99 \\
\hline 19 & 1988 & 959 & 0.48 & 9770 & 4.87 & 9.083756 & 9.187072 & 0.10 & 6.71 \\
\hline 20 & 1989 & 1249 & 0.62 & 11019 & 5.49 & 9.187072 & 9.307376 & 0.12 & 5.76 \\
\hline 21 & 1990 & 1332 & 0.66 & 12351 & 6.16 & 9.307376 & 9.421492 & 0.11 & 6.07 \\
\hline 22 & 1991 & 1834 & 0.91 & 14185 & 7.07 & 9.421492 & 9.55994 & 0.14 & 5.01 \\
\hline 23 & 1992 & 1868 & 0.93 & 16053 & 8.00 & 9.55994 & 9.683651 & 0.12 & 5.60 \\
\hline
\end{tabular}




\begin{tabular}{|c|c|c|c|c|c|c|c|c|c|}
\hline \multicolumn{10}{|c|}{ Table 2: Contd., } \\
\hline 24 & 1993 & 2100 & 1.05 & 18153 & 9.05 & 9.683651 & 9.806591 & 0.12 & 5.64 \\
\hline 25 & 1994 & 3192 & 1.59 & 21345 & 10.64 & 9.806591 & 9.968573 & 0.16 & 4.28 \\
\hline 26 & 1995 & 3720 & 1.85 & 25065 & 12.50 & 9.968573 & 10.12923 & 0.16 & 4.31 \\
\hline 27 & 1996 & 4586 & 2.29 & 29651 & 14.78 & 10.12923 & 10.29725 & 0.17 & 4.12 \\
\hline 28 & 1997 & 5268 & 2.63 & 34919 & 17.41 & 10.29725 & 10.46079 & 0.16 & 4.24 \\
\hline 29 & 1998 & 5434 & 2.71 & 40353 & 20.12 & 10.46079 & 10.60542 & 0.14 & 4.79 \\
\hline 30 & 1999 & 6463 & 3.22 & 46816 & 23.34 & 10.60542 & 10.75398 & 0.15 & 4.66 \\
\hline 31 & 2000 & 7590 & 3.78 & 54406 & 27.12 & 10.75398 & 10.90423 & 0.15 & 4.61 \\
\hline 32 & 2001 & 7496 & 3.74 & 61902 & 30.86 & 10.90423 & 11.03331 & 0.13 & 5.37 \\
\hline 33 & 2002 & 8777 & 4.38 & 70679 & 35.24 & 11.03331 & 11.1659 & 0.13 & 5.23 \\
\hline 34 & 2003 & 10618 & 5.29 & 81297 & 40.53 & 11.1659 & 11.30586 & 0.14 & 4.95 \\
\hline 35 & 2004 & 12265 & 6.11 & 93562 & 46.64 & 11.30586 & 11.44638 & 0.14 & 4.93 \\
\hline 36 & 2005 & 12506 & 6.23 & 106068 & 52.88 & 11.44638 & 11.57184 & 0.13 & 5.52 \\
\hline 37 & 2006 & 13601 & 6.78 & 119669 & 59.66 & 11.57184 & 11.69248 & 0.12 & 5.74 \\
\hline 38 & 2007 & 15125 & 7.54 & 134794 & 67.20 & 11.69248 & 11.8115 & 0.12 & 5.82 \\
\hline 39 & 2008 & 14096 & 7.03 & 148890 & 74.22 & 11.8115 & 11.91096 & 0.10 & 6.97 \\
\hline 40 & 2009 & 9851 & 4.91 & 158741 & 79.13 & 11.91096 & 11.97503 & 0.06 & 10.82 \\
\hline 41 & 2010 & 10262 & 5.12 & 169003 & 84.25 & 11.97503 & 12.03767 & 0.06 & 11.06 \\
\hline 42 & 2011 & 10437 & 5.20 & 179440 & 89.45 & 12.03767 & 12.0976 & 0.06 & 11.56 \\
\hline 43 & 2012 & 10756 & 5.36 & 190196 & 94.82 & 12.0976 & 12.15581 & 0.06 & 11.90 \\
\hline 44 & 2013 & 10402 & 5.19 & 200598 & 100.00 & 12.15581 & 12.20906 & 0.05 & 13.01 \\
\hline & Total & $\mathbf{2 0 0 5 9 8}$ & $\mathbf{1 0 0 . 0 0}$ & & & & & & \\
\hline & Avg Paper & $\mathbf{4 5 5 9 . 0 4 5}$ & & & & & & & \\
\hline
\end{tabular}

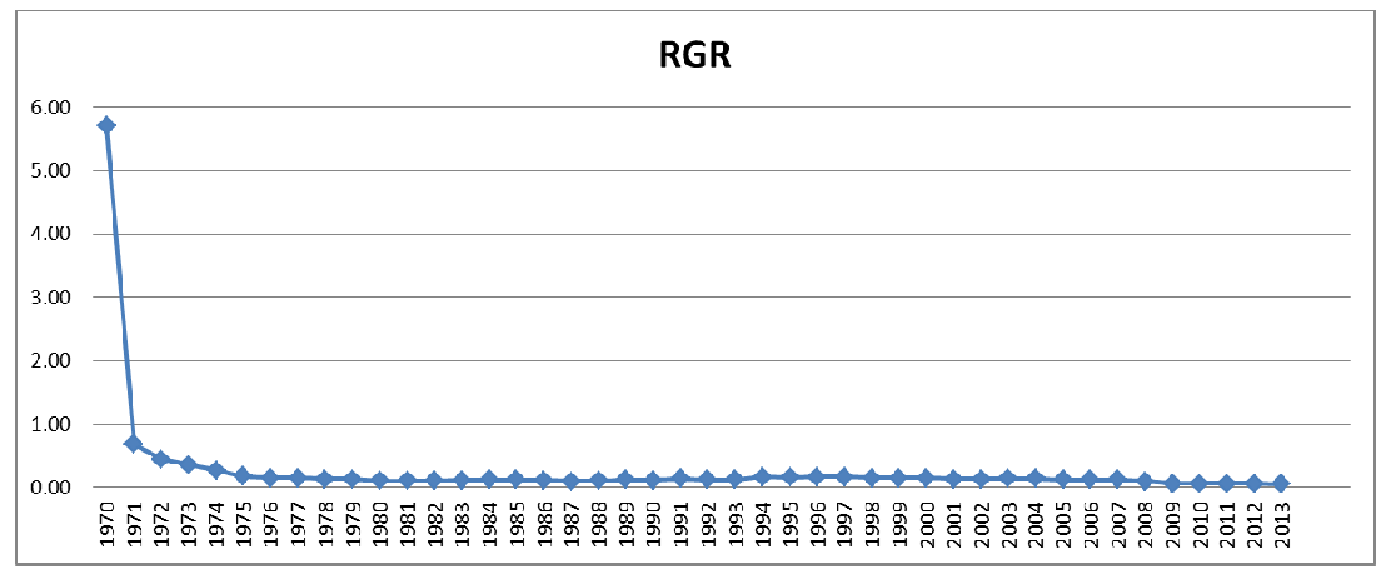

Figure 1: Relative Growth Rate of Crystallography Literature

\section{Doubling time}

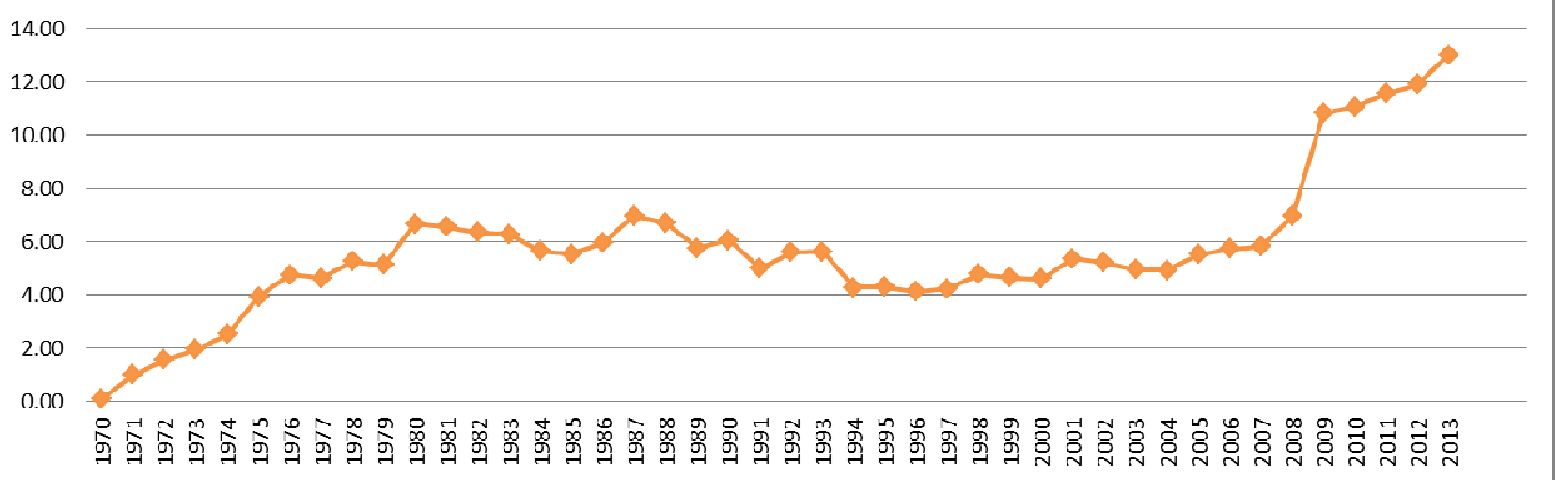

Figure 2: Doubling Time of Crystallography Literature 
The total number of publications, more than 1000 could be seen from the year 1989, till the study period 2013. Also from the year 2003, the publications per year are more than 10000 except in 2009 (9851). The cumulative total of the publication is 2116889. The Ratio of Growth (RoG) varies from 0.05 and 5.70. The RoG value of 5.70 is seen in the year 1970. From the year 1970 onwards, the RoG shows that there is a steady growth of the research output of crystallography. This confirms that the global researchers are interested to publish papers on crystallography. It is seen from the table that Dt values are between 0.12 and 13.01during the years of the study period.

\section{Document Type Distribution}

The publications in Crystallography were contributed in different bibliographic forms such as article, review, proceedings, short survey, notes, book chapters, etc. and the same is shown in Table 3 and figure 3.

Table 3: Document Type Distribution

\begin{tabular}{|c|l|c|c|}
\hline S. No. & Document type & Publications & \% \\
\hline 1 & Article & 175528 & 87.50 \\
\hline 2 & Conference Paper & 12539 & 6.25 \\
\hline 3 & Review & 6864 & 3.42 \\
\hline 4 & Short Survey & 1376 & 0.69 \\
\hline 5 & Note & 657 & 0.33 \\
\hline 6 & Letter & 645 & 0.32 \\
\hline 7 & Editorial & 598 & 0.30 \\
\hline 8 & Conference Review & 176 & 0.09 \\
\hline 9 & Book Chapter & 160 & 0.08 \\
\hline 10 & Erratum & 112 & 0.06 \\
\hline 11 & Book & 82 & 0.04 \\
\hline 12 & Article in Press & 48 & 0.02 \\
\hline 13 & Report & 18 & 0.01 \\
\hline 14 & Undefined & 1795 & 0.89 \\
\hline & & 200598 & 100.00 \\
\hline
\end{tabular}

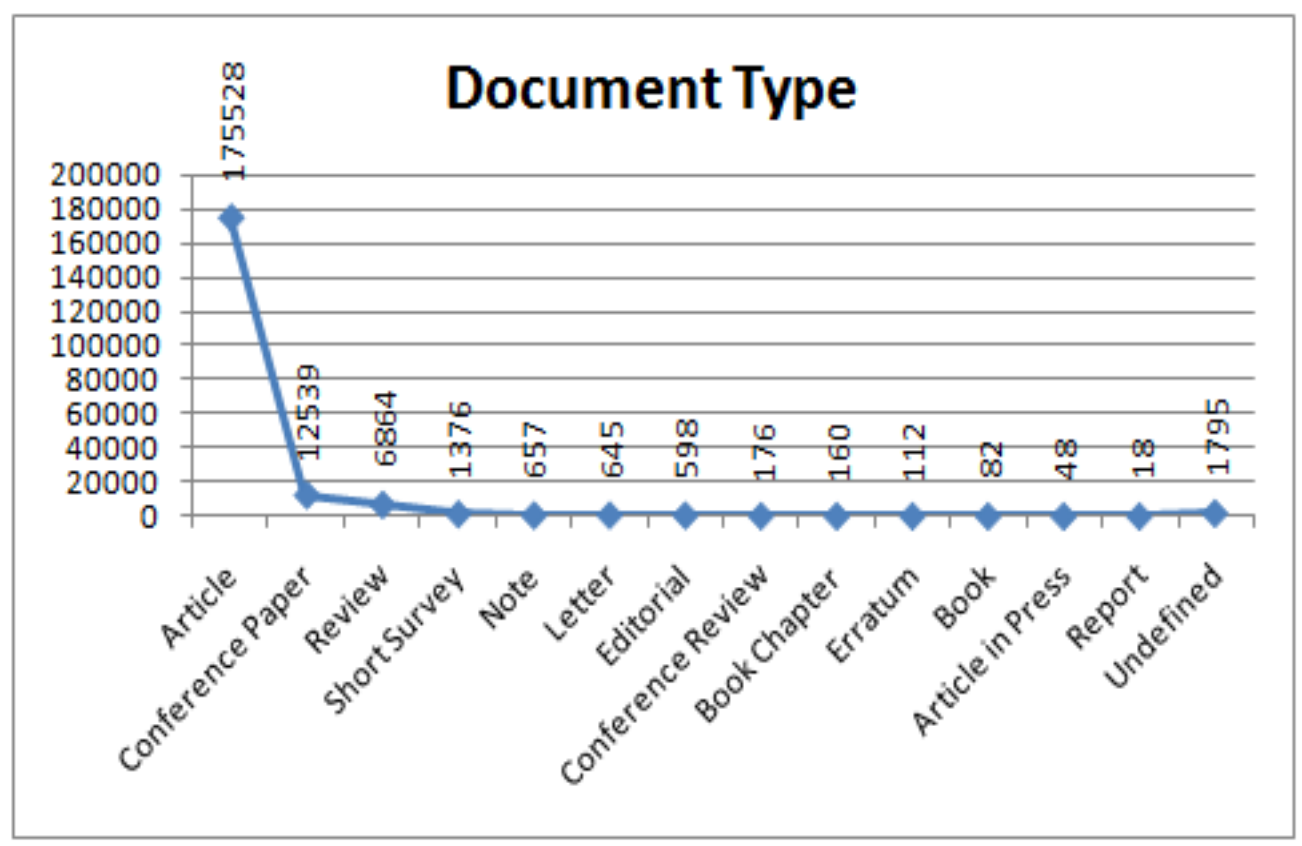

Figure 3: Document Type of the Crystallography Publications 
It is seen from table 3 and figure 3 that the maximum number of articles $175528(87.50 \%)$ is published in journals. This is followed by Conference papers12539 (6.25\%) and Reviews6864 (3.42\%). There are also 1795 (0.89\%) undefined type of publications. It is inferred that, the researchers in global level are interested to publish their research findings in crystallography in journals followed by presenting at conferences.

\section{Language Wise Distribution}

The research outputs on Crystallography were contributed in more than 29 languages and the contribution in the top 30 languages is shown in Table 4.

Table 4: Language Wise Distribution

\begin{tabular}{|c|c|c|c|}
\hline S. No. & Language & Papers & Percentage \\
\hline 1 & English & 196551 & 97.98 \\
\hline 2 & Chinese & 1105 & 0.55 \\
\hline 3 & Japanese & 708 & 0.35 \\
\hline 4 & German & 593 & 0.30 \\
\hline 5 & Russian & 476 & 0.24 \\
\hline 6 & French & 412 & 0.21 \\
\hline 7 & Spanish & 67 & 0.03 \\
\hline 8 & Italian & 36 & 0.02 \\
\hline 9 & Portuguese & 26 & 0.01 \\
\hline 10 & Polish & 19 & 0.01 \\
\hline 11 & Hungarian & 18 & 0.01 \\
\hline 12 & Ukrainian & 17 & 0.01 \\
\hline 13 & Korean & 12 & 0.01 \\
\hline 14 & Turkish & 10 & 0.00 \\
\hline 15 & Czech & 9 & 0.00 \\
\hline 16 & Croatian & 6 & 0.00 \\
\hline 17 & Serbian & 6 & 0.00 \\
\hline 18 & Bulgarian & 4 & 0.00 \\
\hline 19 & Dutch & 4 & 0.00 \\
\hline 20 & Danish & 3 & 0.00 \\
\hline 21 & Finnish & 2 & 0.00 \\
\hline 22 & Romanian & 2 & 0.00 \\
\hline 23 & Slovene & 2 & 0.00 \\
\hline 24 & Swedish & 2 & 0.00 \\
\hline 25 & Greek & 1 & 0.00 \\
\hline 26 & Indonesian & 1 & 0.00 \\
\hline 27 & Malay & 1 & 0.00 \\
\hline 28 & Norwegian & 1 & 0.00 \\
\hline 29 & Slovak & 1 & 0.00 \\
\hline \multirow[t]{2}{*}{30} & Others & 503 & 0.25 \\
\hline & Total & 200598 & 100.00 \\
\hline
\end{tabular}

It is noted from the Table 4 that, there are 1, 96, and 551 (97.98) publications contributed in English language, followed by Chinese1105 (0.55) and Japanese 708 (0.35). It is obvious that few of the publications might have been published in multi-language as well.

\section{Country Wise Distribution}

The country wise production, research output in Crystallography is shown in Table 5. The countries with more than 1000 publications were listed out in the table 5. 
Table 5: Country Wise Distribution

\begin{tabular}{|c|c|c|c|}
\hline S. No. & Country & No of Publications & Percentage \\
\hline 1 & United States & 60181 & 30.00 \\
\hline 2 & China & 23044 & 11.49 \\
\hline 3 & United Kingdom & 20146 & 10.04 \\
\hline 4 & Germany & 19831 & 9.89 \\
\hline 5 & Japan & 19296 & 9.62 \\
\hline 6 & France & 13354 & 6.66 \\
\hline 7 & India & 8143 & 4.06 \\
\hline 8 & Canada & 7438 & 3.71 \\
\hline 9 & Italy & 6635 & 3.31 \\
\hline 10 & Spain & 5798 & 2.89 \\
\hline 11 & Russian Federation & 5141 & 2.56 \\
\hline 12 & Australia & 4857 & 2.42 \\
\hline 13 & Switzerland & 4502 & 2.24 \\
\hline 14 & Poland & 4259 & 2.12 \\
\hline 15 & South Korea & 3746 & 1.87 \\
\hline 16 & Sweden & 3318 & 1.65 \\
\hline 17 & Netherlands & 2853 & 1.42 \\
\hline 18 & Brazil & 2265 & 1.13 \\
\hline 19 & Taiwan & 2243 & 1.12 \\
\hline 20 & Belgium & 2009 & 1.00 \\
\hline 21 & Denmark & 1867 & 0.93 \\
\hline 22 & Austria & 1803 & 0.90 \\
\hline 23 & Israel & 1740 & 0.87 \\
\hline 24 & Malaysia & 1613 & 0.80 \\
\hline 25 & Turkey & 1521 & 0.76 \\
\hline 26 & Czech Republic & 1426 & 0.71 \\
\hline 27 & Finland & 1279 & 0.64 \\
\hline 28 & Portugal & 1258 & 0.63 \\
\hline 29 & Hong Kong & 1251 & 0.62 \\
\hline 30 & Singapore & 1231 & 0.61 \\
\hline 31 & New Zealand & 1210 & 0.60 \\
\hline 32 & Ukraine & 1181 & 0.59 \\
\hline 33 & Iran & 1070 & 0.53 \\
\hline 34 & Mexico & 1062 & 0.53 \\
\hline 35 & Greece & 1036 & 0.52 \\
\hline 36 & South Africa & 1024 & 0.51 \\
\hline
\end{tabular}

Table 5 reveals that collaborative researches have been carried out in the area Crystallography, beyond the territory. United States of America holds the key position with 60,181 (30.00\%) of total publications, which is followed by China and UK. India holds 7th place with 8,143 (4.06\%) publications. The countries with more than 100 publications were listed out in the table 5. This shows that India's contribution in Crystallography is in a remarkable position.

\section{Core Journals on Crystallography}

The source publication with more than 1000 is enumerated in table 6 with the total no. of publications along with the percentage.

Table 6: The Source Titles with More than 1000 Publications

\begin{tabular}{|c|l|c|c|}
\hline S. No. & \multicolumn{1}{|c|}{ Source Title } & $\begin{array}{c}\text { No of } \\
\text { Publications }\end{array}$ & Percentage \\
\hline 1 & Acta Crystallographic Section E Structure Reports Online & 15645 & 7.80 \\
\hline 2 & Journal of the American Chemical Society & 5980 & 2.98 \\
\hline
\end{tabular}




\begin{tabular}{|c|c|c|c|}
\hline 3 & Journal of Molecular Biology & 5708 & 2.85 \\
\hline 4 & Inorganic Chemistry & 5266 & 2.63 \\
\hline 5 & ActaCrystallographica Section C Crystal Structure Communications & 5056 & 2.52 \\
\hline 6 & Journal of Biological Chemistry & 4612 & 2.30 \\
\hline 7 & Biochemistry & 4538 & 2.26 \\
\hline 8 & ActaCrystallographica Section D Biological Crystallography & 4010 & 2.00 \\
\hline 9 & $\begin{array}{l}\text { ActaCrystallographica Section F Structural Biology and Crystallization } \\
\text { Communications }\end{array}$ & 2951 & 1.47 \\
\hline 10 & Journal of Applied Crystallography & 2927 & 1.46 \\
\hline 11 & $\begin{array}{l}\text { Proceedings of the National Academy of Sciences of the United States } \\
\text { of America }\end{array}$ & 2870 & 1.43 \\
\hline 12 & Organometallics & 2536 & 1.26 \\
\hline 13 & Journal of Medicinal Chemistry & 2480 & 1.24 \\
\hline 14 & Journal of Organic Chemistry & 2311 & 1.15 \\
\hline 15 & Dalton Transactions & 2296 & 1.14 \\
\hline 16 & Chemical Communications & 2003 & 1.00 \\
\hline 17 & Structure & 1942 & 0.97 \\
\hline 18 & Journal of Organometallic Chemistry & 1769 & 0.88 \\
\hline 19 & InorganicaChimicaActa & 1743 & 0.87 \\
\hline 20 & Bioorganic and Medicinal Chemistry Letters & 1670 & 0.83 \\
\hline 21 & Polyhedron & 1663 & 0.83 \\
\hline 22 & Nature & 1619 & 0.81 \\
\hline 23 & Chemistry A European Journal & 1579 & 0.79 \\
\hline 24 & AngewandteChemie International Edition & 1564 & 0.78 \\
\hline 25 & Tetrahedron Letters & 1559 & 0.78 \\
\hline 26 & Tetrahedron & 1498 & 0.75 \\
\hline 27 & Protein Science & 1371 & 0.68 \\
\hline 28 & Proteins Structure Function and Genetics & 1345 & 0.67 \\
\hline 29 & Science & 1267 & 0.63 \\
\hline 30 & Journal of the Chemical Society Dalton Transactions & 1158 & 0.58 \\
\hline 31 & Journal of Synchrotron Radiation & 1094 & 0.55 \\
\hline 32 & ActaCrystallographica Section A Foundations of Crystallography & 1077 & 0.54 \\
\hline 33 & Organic Letters & 1070 & 0.53 \\
\hline 34 & Journal of Crystal Growth & 1008 & 0.50 \\
\hline
\end{tabular}

In general, the journals were the most preferred means of communications in Crystallography. The Table 6 shows the list of 34 journals, which carry more than 1000 contributions in the field of Crystallography. Among different sources which carry research outputs, 'ActaCrystallographica Section E Structure Reports Online' is ranked first with the 15645 (7.80\%) records followed by 'Journal of the American Chemical Society' with 5980 (2.98\%) and 'Journal of Molecular Biology' with 5708 (2.85\%) publications.

\section{Highly Published Institutions}

The top 123 organizations contributing more than 500 research publications in Crystallography were identified and the same is shown in Table 7.

Table 7: Highly Published Institutions

\begin{tabular}{|l|l|c|c|}
\hline S. No & \multicolumn{1}{|c|}{ Institution } & Papers & Percentage \\
\hline 1 & Osaka University & 2050 & 1.02 \\
\hline 2 & University of Tokyo & 1926 & 0.96 \\
\hline 3 & CNRS Centre National de la RechercheScientifique & 1879 & 0.94 \\
\hline 4 & University of Oxford & 1824 & 0.91 \\
\hline
\end{tabular}


Table 7: Contd.,

\begin{tabular}{|l|l|c|c|}
\hline \multicolumn{3}{|c|}{ Table 7: Contd., } \\
\hline 5 & Kyoto University & 1801 & 0.90 \\
\hline 6 & Scripps Research Institute & 1654 & 0.82 \\
\hline 7 & UC Berkeley & 1401 & 0.70 \\
\hline 8 & University of Cambridge & 1295 & 0.65 \\
\hline 9 & University of California, San Diego & 1204 & 0.60 \\
\hline 10 & Tokyo Institute of Technology & 1194 & 0.60 \\
\hline 11 & European Synchrotron Radiation Facility & 1158 & 0.58 \\
\hline 12 & Cornell University & 1136 & 0.57 \\
\hline 13 & Eidgenossische TechnischeHochschule Zurich & 1128 & 0.56 \\
\hline 14 & Imperial College London & 1120 & 0.56 \\
\hline 15 & Texas A and M University & 1111 & 0.55 \\
\hline 16 & Argonne National Laboratory & 1093 & 0.54 \\
\hline 17 & Massachusetts Institute of Technology & 1075 & 0.54 \\
\hline 18 & University of Toronto & 1043 & 0.52 \\
\hline 19 & University of Manchester & 1028 & 0.51 \\
\hline 20 & ConsiglioNazionaledelleRicerche & 1021 & 0.51 \\
\hline
\end{tabular}

Table 7 shows that Osaka University holds first place in contributing research productions in Crystallography with $2050(1.02 \%)$ of the total publications, which is followed by the University of Tokyo in $1926(0.96 \%)$ and CNRS Centre National de la RechercheScientifique 1879 (0.94\%) publications.

\section{Highly Published Authors}

The most productive authors based on their contribution in Crystallography are identified, and the authors with more than 200publications are shown Table 8.

Table 8: Top Authors

\begin{tabular}{|c|l|c|c|}
\hline S. No. & Author Name & Papers & Percentage \\
\hline 1 & Ng, S.W. & 598 & 0.30 \\
\hline 2 & Rheingold, A.L. & 394 & 0.20 \\
\hline 3 & Huber, R. & 393 & 0.20 \\
\hline 4 & Bolte, M. & 382 & 0.19 \\
\hline 5 & Fun, H.K. & 372 & 0.19 \\
\hline 6 & Buyukgungor, O. & 331 & 0.17 \\
\hline 7 & Glidewell, C. & 314 & 0.16 \\
\hline 8 & Clegg, W. & 305 & 0.15 \\
\hline 9 & Yokoyama, S. & 302 & 0.15 \\
\hline 10 & Butcher, R.J. & 299 & 0.15 \\
\hline 11 & Jones, P.G. & 292 & 0.15 \\
\hline 12 & Spek, A.L. & 278 & 0.14 \\
\hline 13 & Cotton, F.A. & 275 & 0.14 \\
\hline 14 & Gao, S. & 270 & 0.13 \\
\hline 15 & Slawin, A.M.Z. & 266 & 0.13 \\
\hline 16 & Hursthouse, M.B. & 266 & 0.13 \\
\hline 17 & Linden, A. & 262 & 0.13 \\
\hline 18 & Williams, D.J. & 257 & 0.13 \\
\hline 19 & Tiekink, E.R.T. & 248 & 0.12 \\
\hline 20 & Low, J.N. & 243 & 0.12 \\
\hline 21 & Fronczek, F.R. & 242 & 0.12 \\
\hline 22 & Yathirajan, H.S. & 238 & 0.12 \\
\hline 23 & Olmstead, M.M. & 233 & 0.12 \\
\hline 24 & Wang, D.Q. & 233 & 0.12 \\
\hline 25 & Ravikumar, K. & 230 & 0.11 \\
\hline 26 & Huo, L.H. & 227 & 0.11 \\
\hline & & & \\
\hline
\end{tabular}




\begin{tabular}{|l|l|r|l|}
\multicolumn{4}{|c|}{ Table 8: Contd., } \\
\hline 27 & Howard, J.A.K. & 219 & 0.11 \\
\hline 28 & Drew, M.G.B. & 213 & 0.11 \\
\hline 29 & Wilson, I.A. & 213 & 0.11 \\
\hline 30 & Fun, H.K. & 203 & 0.10 \\
\hline
\end{tabular}

Table 8 reveals that 30 global authors contributed more than 200 publications each. Among the 30 authors, Ng, S.W. Published 598 (0.30\%) articles followed by Rheingold, A.L. 394 (0.20\%) and Huber, R 393 (0.20\%), who holds top three positions during the study period.

\section{CONCLUSIONS}

The research output on the crystallography has been studied in the light of global research using global database, SCOPUS. The data, which were analyzed, is for the period 1970 to 2013 . A total of 2, 00,598 records was retrieved from the database for analysis purpose. This study reported the findings to determine the publication trend, with respect to growth of literature on year wise, language wise and country wise with the bibliographic form, where the publications are published. This study also enumerated the affiliation of the authors, source titles and the top global authors. The objectives and the hypotheses set for this study were thoroughly investigated. The results computed were quite encouraging, particularly on the use of laser in medical sciences. This study also found that, there is a steady growth on the research publications on laser in medical sciences, and almost all the developed and developing countries contributed to the research on the use of laser in medical sciences. It is also to note that Indian contribution is remarkable in this research.

\section{REFERENCES}

1. Balasubramani, C., et al (2014), Growth of Research Output in Genetic Engineering: A Scientometric Study, Journal of Advances in Library and Information Science, 3 (3), 179-185.

2. Bradford, S.C (1934), Sources of information on specific subjects. Engineering: An Illustrated Weekly, 3550, 85-86.

3. Crystallography matters by United Nations Educational Scientific and Cultural Organization, Paris, France. 2013.

4. Garfield, E. (1979), Citation Indexing Its Theory and Application in Science, Technology and Humanities. New York: John wily and Sons.

5. Gopalakrishnan, S, Gopalakrishnan, S, Bathrinarayanan,A L, Tamizhchelvan, M, (2015), Uncited Publications in MEMS Literature: A Bibliometric Study, DESIDOC Journal of Library \& Information Technology, 35 (2), 113-123.

6. Gupta B M et al. (2002), Modeling the growth of world social science literature, Scientometrics. 53(H):161-164

7. http://www.scopus.com

8. https://en.wikipedia.org/wiki/crystallography

9. Kalaiselvi. E and Gopalakrishnan. S (2017). Global research output on laser in medical field: a bibliometric study, International Journal of Library Science and Research (IJLSR), 7 (2), 13-26.

10. Karpagam, R., Gopalakrishnan, S., Natarajan, M. et al. (2011), Mapping of nanoscience and nanotechnology research in India: a scientometric analysis, 1990-2009, Scientometrics, 89: 501. doi:10.1007/s11192-011-0477-8

11. Keerti, Bala J and Kumar S (2011). Indian contribution to World Soyabean Research: Measurement of research productivity of soyabean scientists. 8th International CALIBER - 2011, Goa University, Goa, March 02-04, 2011.

12. Lotka, A. J. (1926). The frequency distribution of scientific productivity, Journal of the Washington Academy of Sciences, 16 
(12), 317-322.

13. Mooghali, A. et al. (2011), Scientometric Analysis of the Scientometric Literature, International Journal of Information Science and Management, 9(1): 19-31.

14. Nalimov, V. and Mulchenko, Z. M. (1969), Naukometrija: IzuchenijerazvitijanaukikakInformacinnege process.M: Nauka, 192.

15. Pritchard A (1969), Statistical Bibliography or Bibliometrics, Journal of Documentation, 25 (4), pp.348-349

16. Ramesh, P et al(2014), Growth of Indian Research Output on Brain Tumour: A Bibliometric Study Using Scopus Database, European Academic Research, II (7).

17. Su HN, Lee PC (2010), Mapping knowledge structure by keyword co-occurrence: a first look at journal papers in Technology Foresight, Scientometrics, 85: 65-79.

18. UN announcement "International Year of Crystallography". iycr2014.org. 12 July 2012

19. Venkatesh M et al(2013), Growth of Literature on Climate Change Research: A Scienrometric study, Journal of Advances in Library and Information Science, 2 (4), 236-242. 
